\title{
Evidence Emerging from the Survey on European Union Timber Regulation [REG. (EU) 995/2010] in Italy
}

\author{
Hadžić Nermin, Carbone Francesco* \\ Department for Innovation in Biological, Agro-Food and Forest Systems, University of Tuscia, Viterbo, Italy \\ Email: ${ }^{\star}$ fcarbone@unitus.it
}

How to cite this paper: Nermin, H., \& Francesco, C. (2022). Evidence Emerging from the Survey on European Union Timber Regulation [REG. (EU) 995/2010] in Italy. Open Journal of Forestry, 12, 142-161. https://doi.org/10.4236/ojf.2022.121008

Received: November 8, 2021

Accepted: January 26, 2022

Published: January 29, 2022

Copyright (อ 2022 by author(s) and Scientific Research Publishing Inc. This work is licensed under the Creative Commons Attribution International License (CC BY 4.0).

http://creativecommons.org/licenses/by/4.0/

\section{(c) (i) Open Access}

\begin{abstract}
Illegal logging is a pervasive problem of major international concern that causes many negative social, economical and environmental consequences. EUTR is a tool adopted in 2010 and entered into force in 2013 to stop the trade of timber illegally logged within the EU market. The implementation in Italy is still in progress and varies among regions. This study considers the respondents' opinions on different EUTR characteristics, implementation processes and compliance activities. Taking Italy as an example, the questionnaire was delivered to relevant Italian foresters and timber operators in the forest-timber system. Two hypotheses are under verification: 1) if Italian forest-wood-timber sector integrated EUTR into its activity and 2) if the Italian Due Diligence system is a valid model to other countries. The questionnaire has been submitted to the wood industry stakeholders. It has been organized into six sections to collect information about the professional characteristics of respondents, their experiences on EUTR, the opinion about EUTR and FLEGT, the support received on EUTR implementation, the opinion about the checks system, and the role of EUTR in marketing timber products. Questionnaire data have been elaborated in different ways. Conclusion underlines the EUTR Italian system criticalities and some suggestions for a more effective use of EUTR in the wood market. The picture that emerges from the results collected is that the EUTR, although proposed for morally and ethically valid purposes, doesn't have unanimous effectiveness. In particular, EUTR can generate a distortion of the market, new expenditures for importers. Various operators applaud the role of certification schemes for sustainable forest management, which indirectly makes it possible to prevent the aforementioned problem. The Italian EUTR system is working only for satisfying Regulation 995/2010 targets. This must be considered as the starting point; however, three innovative topics could be developed in the future:
\end{abstract}


digitalization and computerization of EUTR certification, integration of EUTR certification with forest certifications schemes and other quality certifications, and use of EUTR in the marketing initiatives.

\section{Keywords}

EUTR, Illegal Logging, Implementation, Questionnaire, Foresters and Timber Operators in the Forest-Timber Systems

\section{Introduction}

Illegal logging is a pervasive problem of major international concern that needs to be addressed at an international scale. The first relevant report in the matter was produced in 1997 by the Intergovernmental Panel Forest (1997) (Economic and Social Council, 1997). In the same year the G8 Summit was held in Denver (USA), five relevant forest issues were included in the Agenda ${ }^{1}$ and the fifth issue was the contrast of illegal logging practice. The G8 launch the Action Program on Forests that would accelerate the global implementation of the sustainable use of forests, including the contrast to the illegal logging trade. This issue has become an aim at an international scale. The main characteristics of the illegal logging prevention strategy are an efficient multi-level governance approach, international cooperation between timber importer and exporters' countries, and adoption of domestic markets regulation.

During the decade 2000-2010, the multilevel forest policy proposed Forest Law Enforcement, Governance and Trade (FLEGT) as the international tool to contrast deforestation and the illegal trade of the logged timber. Major international institutions such as World Bank and FAO have adopted the FLEGT.

In 2003 the Forest Law Enforcement Governance and Trade (FLEGT) Action Plan (Commission of the European Communities, 2003) was adopted from the European Union, where the strategy to fight illegal logging and associated trade was defined. Measures to exclude illegal timber from the EU market, to improve the supply of legal timber and to increase the demand for responsibly produced wood products have been proposed (European Commission, 2013). EUTR was adopted in October 2010 and entered in force 03 march 2013 (Matsson, 2015). Two pillars support the EU FLEGT package, such as:

- Regulation n. 2173/2005, bilateral voluntary agreements, signed with countries that have an important problem of timber illegal logging towards European countries (external trade);

- Regulation n. 995/2010, European Union Timber Regulation (EUTR) or known as timber due diligence, to regulate the timber internal trade.

Focus of this research is the EUTR. It is a complementary tool to FLEGT. EUTR requires that wood traded in the internal market have to be ensured by ${ }^{1}$ The G8 Summit Agenda included: 1) monitoring and assessment; 2) national forest programs; 3) protected areas; 4) private sector; and 5) illegal logging. 
the traceability since its permission to be cut. Subsequently, it excludes the possibility that timber logged illegally can be traded in the EU market.

Despite the clear targets of the regulations, foresters and forest-wood-timber chains operators they have to modify acts and to introduce new administrative process for selling their wood and timber products legally. Implementation requires that operators take action according to the new norms, rules or program (Krott, 2005).

The implementation is still in progress in most EU Member States, and market operators are insufficiently aware of their respective duties (Köthke, 2020). Italy is a country with relevant international timber trade both at the EU and extra-EU level. It is characterized by consistent internal timber production largely used for fuel-wood, however the wood industries are largely timber import-dependent of raw material or semi-finished timber, while final products are allocated in the global market.

This research is the first developed in Italy on the EUTR topic. The aim is to investigate the current state of EUTR implementation on business activities of the Italian foresters and timber operators in the forest-timber system (thereafter operators) and to analyze their experiences. Around $98 \%$ of the total wood used by the Italian wood processing industry is imported (Oliver, 2011). Many questions about EUTR implementation are arising among Italian operators and still need to be addressed (Andrighetto et al., 2015). There are two hypotheses behind this research: 1) have the Italian forest-wood-timber operators integrated EUTR into the ordinary activity? and 2) is Italy a valid model to other timber import EU and extra-EU countries?

\section{Material and Method}

EUTR researches have started in the last decade. The main method of study has been surveying the forestry and timber operators. Hein and Hoare (2014) surveyed on EUTR Competent Authorities, using investigating case studies approach to create relevant questions. Pra (2015) surveyed the private forest owners on the EUTR. A questionnaire, articulated in sections, has been developed and qualitative information was collected and elaborated.

However, preliminary steps of the research have been:

- to define the Italian forest-wood-timber operators list;

- to create the dedicated questionnaire.

\subsection{Operators Identification}

List of operators was created by using the databases of FSC and PEFC certified forest enterprises. All of the PEFC and FSC certified enterprises have obligation to share their experiences. Also, they feel more comfortable and confident to get and to share information. Following these assumptions, these operators have been contacted to collect other relevant operators and enrich the stakeholder list. The list of operators was supplemented by the snowball sampling technique (Glen, 2014). The total number of relevant operators is $n .106$ to which were de- 
livered the questionnaire. Respondents are employed in the public and private sectors as well as research institutions. They have various positions and professional backgrounds in the forest-timber system, such as:

- the managers of forest companies;

- the agents involved in national and international timber trade;

- forestry consultants;

- forest owners;

- purchasing manager and delegate for forest management;

- importers;

- national and international timber dealer;

- sawmill and timber trade representatives;

- administrative staff in the local forestry offices; and

- technical staff of local forestry and environmental offices.

\subsection{The Questionnaire}

Adopting the model of Pra (2015) questionnaire, a dedicated questionnaire has been developed and submitted to foresters and forest-wood-timber chain operators (Table 1).

The questionnaire is divided into 6 sections and it comprises of 10 open-ended and 15 close-ended questions. The survey was conducted in an online format using Google Forms. In the open ended questions, respondents could use the multiple-choice option, checkboxes or Yes/No answers. Content of the six sections are:

- First section is designed to obtain information on the professional profile of respondents (such as working area and working experience of the respondents);

- Second section is focused on the respondents experience in regard to the EUTR;

- Third section is designed to collect respondent's opinions on the relationship between timber produced in Europe and the timber imported with FLEGT license;

- Fourth section collected the respondent's opinions on the support level the operators received for the EUTR implementation;

- Fifth section was related to conformity checks conducted by the Competent Authority;

- Sixth section was designed to collect the stakeholder's opinions if they use the EUTR in conventional and un-conventional way.

\subsection{Mode of Data Elaboration of the Survey}

All data in the questionnaire is elaborated by using one of the following three modes:

- Categorical data; the data is divided into categories and presented by the graphs and tables. It is used for close-ended questions with only a single choice option. 
Table 1. Questionnaire.

\section{Question}

1. What is your role in the forestry sector?

2. In which region do you work?

3. What is the most prevalent type of forest in the region in which you work?

4. What is the most important tree species in the area in which you work?

5. What is the most prevalent use of timber in the area in which you work?

6. To which region is shifted the major part of the raw wood material produced in the area in which you work?

7. How did you find out that the EU has introduced the EUTR?

8. In your opinion, what do you think is the main motive for which the EU has introduced the EUTR?

9. Do you think that the EUTR is an efficient system to combat the introduction of illegal timber on the Italian market? Can you please explain why?

10. In the experience you acquired in the application of the EUTR, have you encountered difficulties in operating in compliance with the regulation? If yes, can you please explain what the difficulties are?

11. Does the EUTR put obligation for operators to carry out activity accordingly to DDS? Have you provided for or participated in the drafting of DDS?

12. While carrying out your activity, which of the information below, you had to deliver for the DDS purposes?

13. Are additional costs recorded by your company (e.g. administrative costs, adjustment costs etc.)? If so, what are the types of additional costs? Can you express, in percentage terms, the relative image of the costs recorded compared to those normally incurred before the EUTR has entered into force?

14. Are you familiar with timber sales with FLEGT license?

15. Have you had a chance to see cases of harmonized administrative procedures between FLEGT and EUTR?

16. Have you recorded cases in which timber with FLEGT license has generated additional bureaucracy compared to timber of EU origin?

17. Has the marketing of timber under the FLEGT license generated additional costs compared to the costs due to the management of the DDS of the wood of EU origin?

18. Do you think that the operators need further support to fulfill their obligation under the EUTR? If so, what would be the most appropriate support to ensure?

19. In the course of your experience, starting from 3 March 2013, the date when the EUTR was took into force, until today, how many checks have you recorded by the Competent Authority in compliance with the EUTR requirements? What kinds of checks have been carried out?

20. Are you aware of any negative assessments resulting from checks on the companies? If yes, can you indicate the type of infringement complained of?

21. Are you aware of any penalties deriving from these offenses? If yes, do you believe that these penalties are commensurate with the company's income capacity? Can you explain the reasons? 


\section{Continued}

22. Are you aware of information initiatives related to the entry into force of the EUTR regulation? If yes to answer who was responsible for these initiatives?

23. While carrying out your activity, did you do your best to spread the information on EUTR to other operators in the sector?

24. If yes to the question n. 23, can you explain how did you do this activity?

25. Do you think that the EUTR is or can become a useful marketing tool for the companies you know or for the general forestry sector? If yes, can you explain to us how it could be used as a marketing tool?

- Categorical data and the aggregation of data; the data is divided into categories and presented by the graphs and tables. It is used for close-ended questions with multiple-choice options.

- Synthesis of answers; the answers to the open-ended question were presented as a synthesis below the related close-ended question.

The modes of data elaboration can be found in the following table (Table 2).

\section{Results}

The survey was conducted in the period from November 2019 to March 2020. Collected data were inserted in the MS Excel and processed in a way to present the results in figures. Open-ended questions are usually hard to be managed and re-elaborate without influencing the result of the study (Yanow, 2007). The total number of contacted operators is $n$. 106. The total number of responses is $n .44$ and the participation ratio is $41.51 \%$ (Figure 1). The results are reported adopting the organization of the questionnaire.

\section{General information}

The total number of responses is n. 44. Total number of filled questionnaires is n. 25. Operators that aren't familiar with the EUTR are n. 12 (11.32\%), while other n. 7 (6.6\%) answered they are not related to this regulation (Figure 2).

\section{Section n. 1-Socio-demographic information}

The first section of the questionnaire gathered data on the socio-demographic information of the respondents as well as the nature of the activities they are carrying out in the Italian forest sector. The answers to the first question: What is your role in the forestry sector provided us with the backgrounds characteristic of respondents. It shows diverse stakeholder roles. The managers of forest companies prevail with $20 \%$ of the total response, followed by $16 \%$ by each of the agents involved in national and international timber trade and forestry consultants. Other interest groups that responded to the questionnaire are: forest owners, purchasing manager and delegate for forest management, importers, national and international timber dealer, sawmill and timber trader, administrative staff in the local forestry office and technical staff of local forestry offices for the management of the Regional Forest Heritage (Figure 3).

The respondents are employed in 7 regions while 1 respondent answered that 
Table 2. Modes of data elaboration for each of the questions of the survey.

\begin{tabular}{cccc}
\hline Categorical data is presented & $\begin{array}{c}\text { Categorical data and } \\
\text { aggregation of data is presented }\end{array}$ & $\begin{array}{c}\text { Categorical data is presented for the first question } \\
\text { and synthesis of answers for the explanation part }\end{array}$ \\
\hline Questions $1,3,6,11,14,15,16,17,23$ & $2,4,5,7,8,12,24$ & $9,10,13,18,19,20,21,22,25$
\end{tabular}

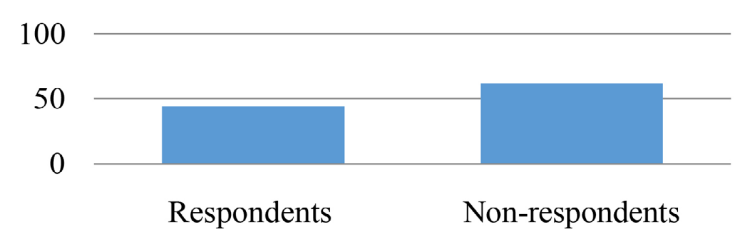

Figure 1. Total number of respondents and non-respondents.

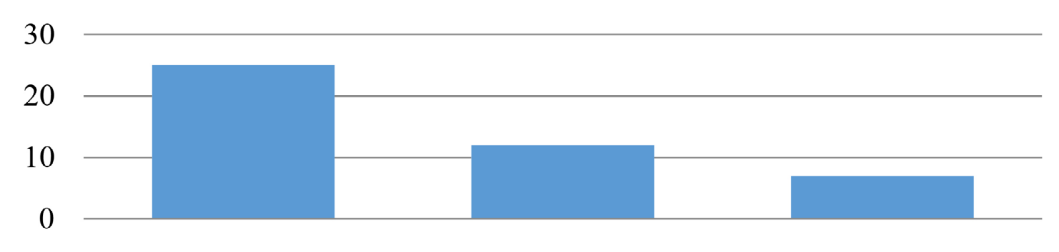

Familiar with the EUTR Not familiar with the EUTR Not related to the EUTR

Figure 2. Number of respondents concerning their knowledge of EUTR.

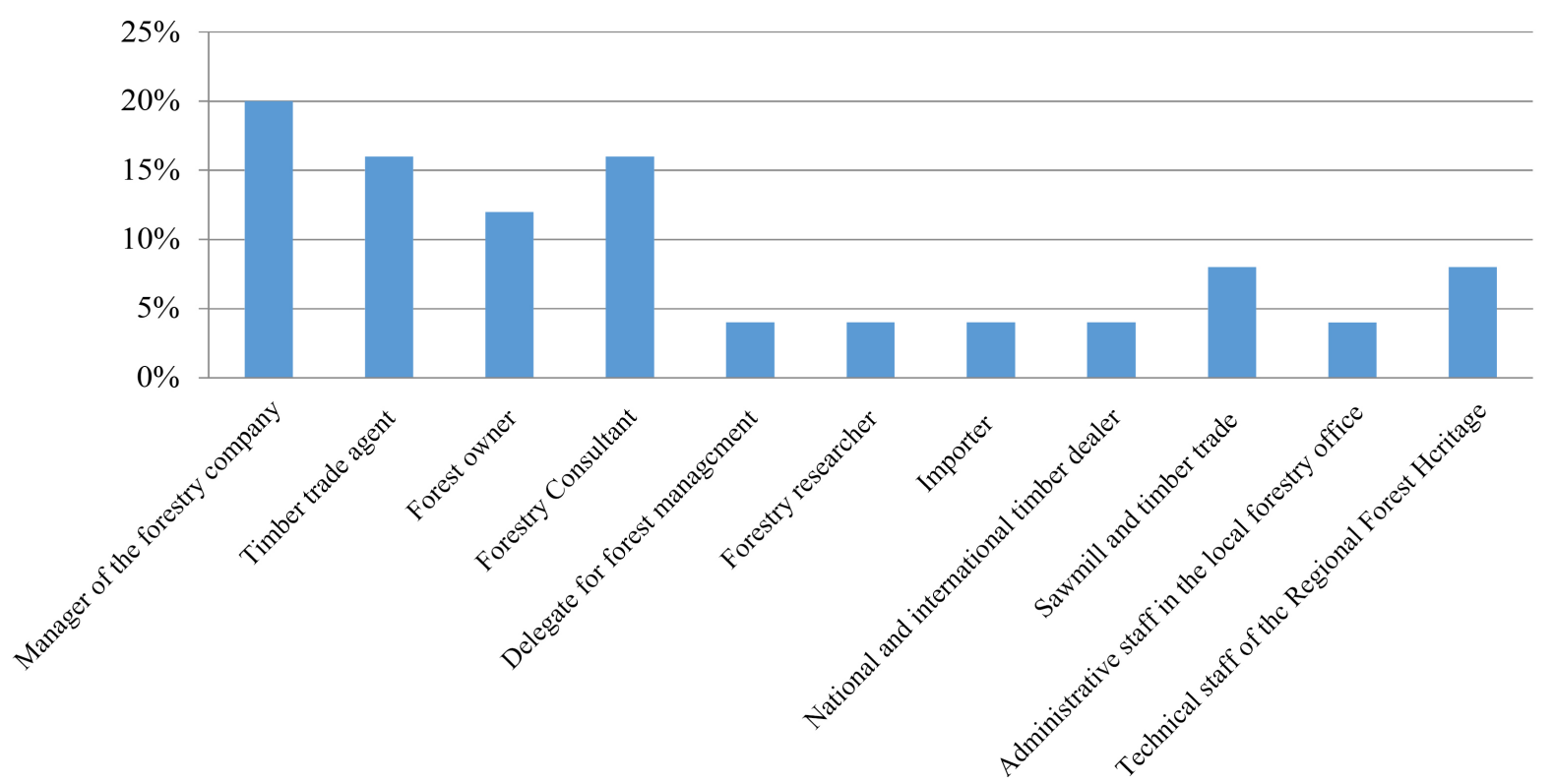

Figure 3. The roles of the respondents in the Italian forestry sector.

he is active in the whole of Italy. The number of answers is only related to the filled questionnaires. Some of the respondents stated they are active in several regions (Figure 4).

Main types of forest in the area of respondent's activities are:

- High forest: $72.7 \%$

- Coppice forest: $18.2 \%$

- Wood plantations: $9.1 \%$ 
This ratio can be seen on the following figure (Figure 5).

Main tree species that are used for the production in the respondent's area of activity are Norway spruce (40.9\%) followed by Larch (22.7\%), Beech (18.2\%) and Fir (18.2\%) (Figure 6).

The final wood product also varies among the respondents. The dominant final products are raw solid construction wood and firewood (Figure 7).

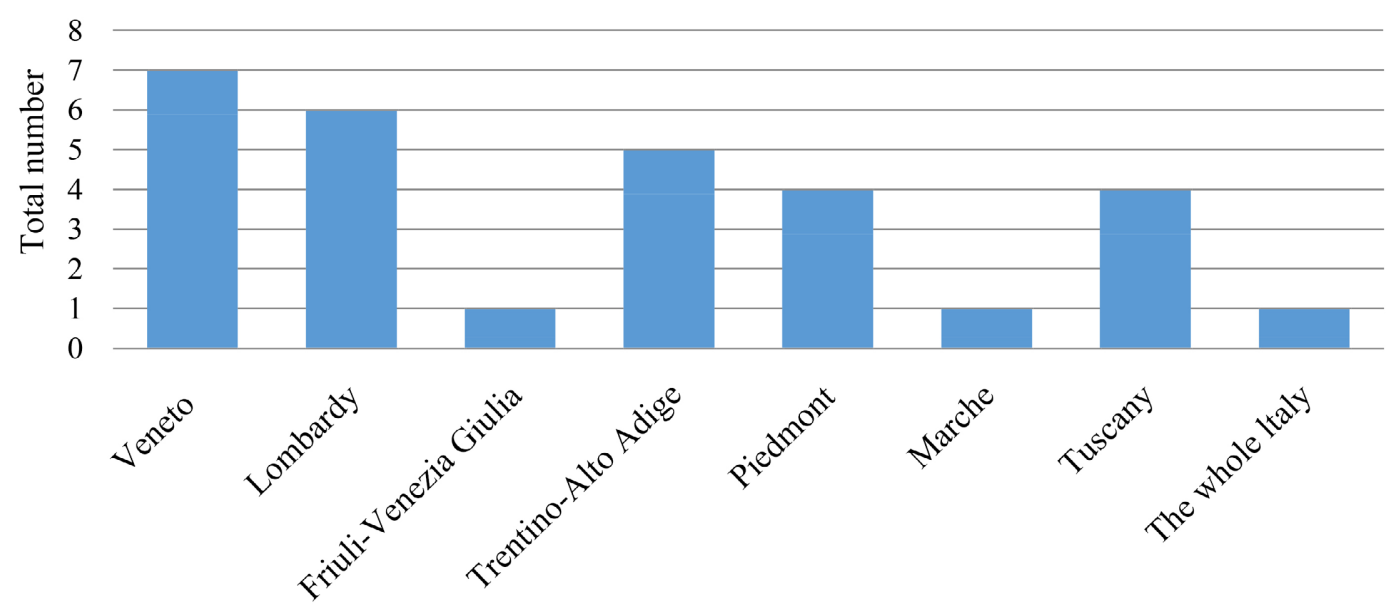

Figure 4. Total number of respondents by regions of Italy.

\section{Types of forests}

- High forest $\quad$ Coppice forest $\quad$ Wood plantations

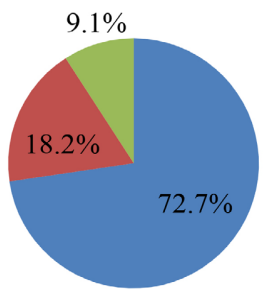

Figure 5. The main types of forests in the areas of respondent's activities.

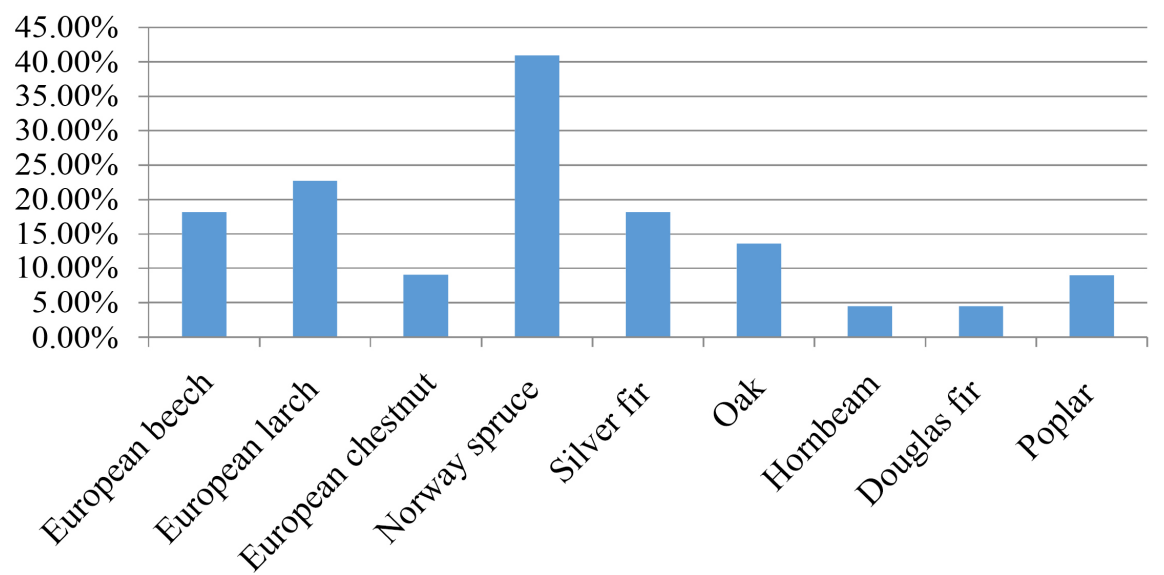

Figure 6. Tree species dominating in the respondent's area of activity. 


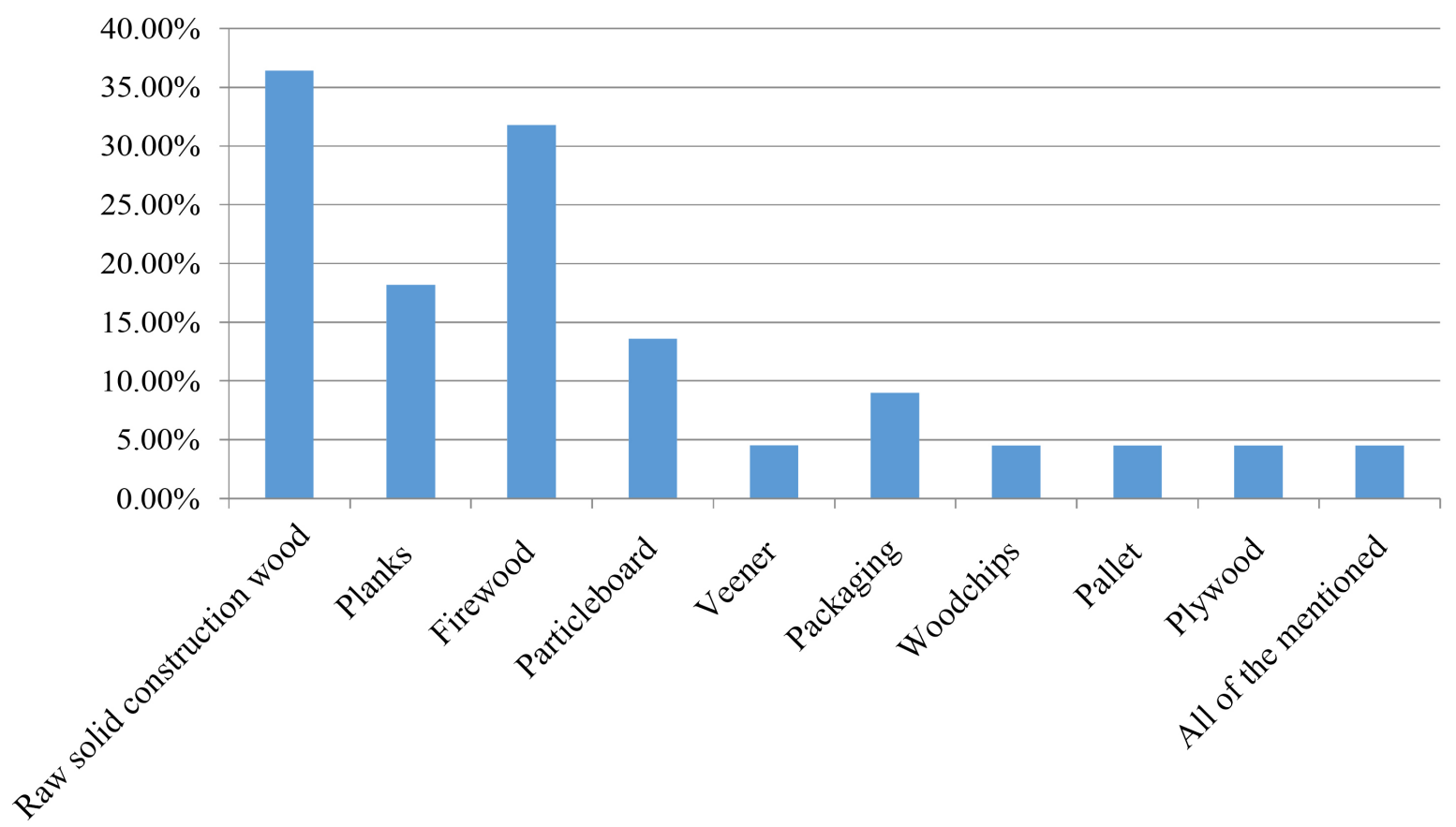

Figure 7. The final wood product in the area of respondent's activities.

The total percentage of respondents' wood production that is transferred either on local, inside the region or outside markets are reported in Figure 8.

Section n. 2-The respondent's experience: knowledge and awareness about the EUTR

In the second section of the questionnaire, the respondents were asked questions regarding their knowledge and awareness about the EUTR. They were also asked to express their opinion about the efficiency of EUTR implementation and enforcement.

According to the answers provided by the respondents, many different sources informed the operators that the EU has introduced the EUTR. As presumed, the majority of respondents identified professional organizations (40\%) and forestry consultants (28\%) as the main sources of the EUTR information. Also, $24 \%$ of the respondents received the information on EUTR from the documents prepared by the Competent Authority (Figure 9).

The respondents have stated almost uniformly (92\%) that the main reason for the EUTR introduction is to contrast the international trade in illegally felled timber in internal EU market. The other frequently selected answer (24\%) was to ensure the traceability of wood production (Figure 10).

Subsequently, the respondents were asked if they think that EUTR is an efficient system to contrast the illegally harvested wood on the European Union timber market. Respondents that answered affirmatively were $54.2 \%$, while $45.8 \%$ of the respondents think the EUTR is not an efficient system.

To this latter respondents group were asked to elaborate their answers to the previous question. They pointed out the uncertainty of wood legality due to different rules, norms and customs that exists among the export countries comparing 


\title{
Wood products market
}

\author{
- Local Inside the region $\quad$ Outside the region
}

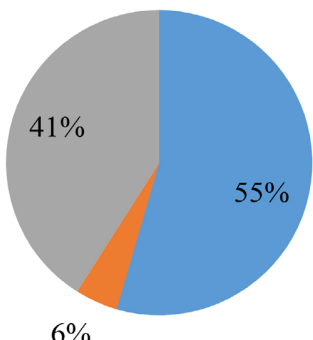

Figure 8. Wood products market of transferred wood products produced by respondents.

\section{Sources of the EUTR information}

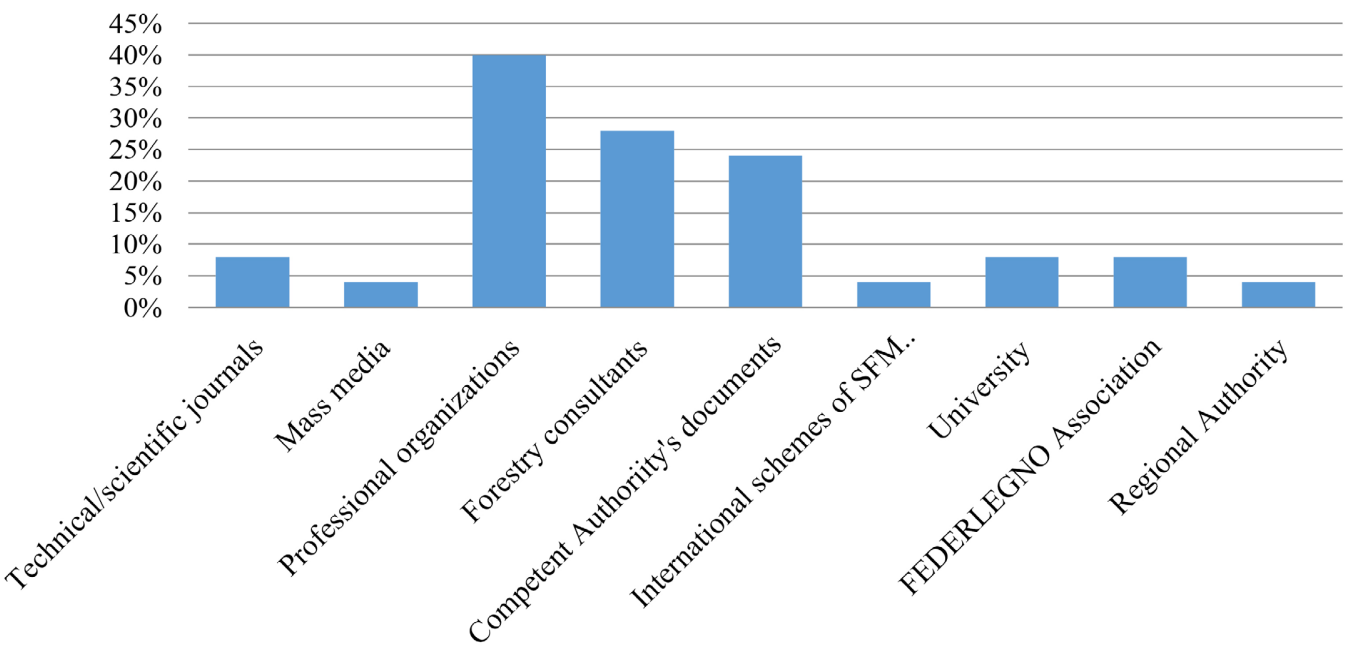

Figure 9. The sources from which respondents received the information that the EU has introduced the EUTR.

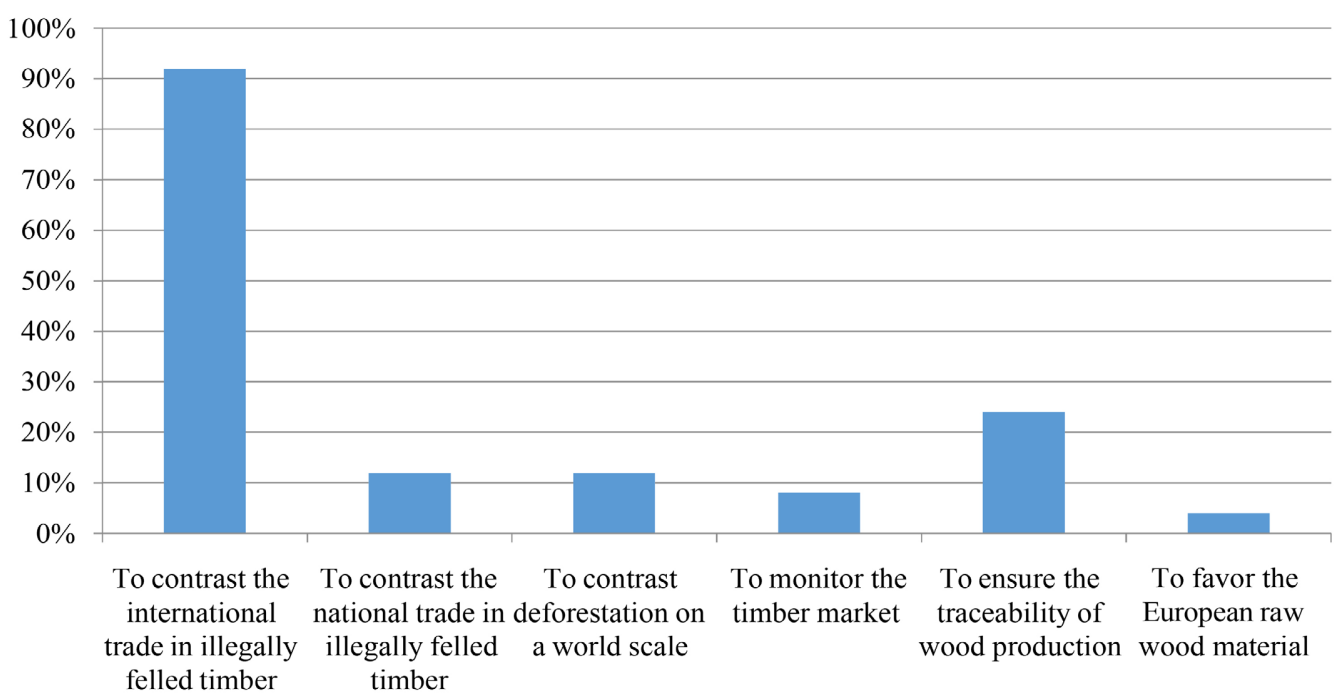

Figure 10. Respondent's opinions on the main reason for the EUTR introduction. 
to import countries, even into European region too. The importing companies, at this stage, declare that exist a strong market imbalance. Exporting companies, being paid in advance, have no interest in taking care of the formal aspects necessary to obtain wood permission for entry in the EU market space. The low quality of the accompanying documents produced by the export companies becomes a burden that bears only on the importing companies.

When the respondents were asked about their experience in the application on the EUTR and if they encountered difficulties to operate in compliance with the EUTR, $69.6 \%$ of the respondents answered they do not have any difficulties while $30.4 \%$ encountered some sort of difficulty. Specifically, respondents have emphasized two aspects: 1) the importance of the PEFC and FSC certification schemes role to produce all the necessary documentation. Those that don't possess this type of certification struggle to produce it; 2) respondents agreed that there is a lack of documental interconnection between buyers and suppliers. Latter are often uncooperative to deliver requested documentation since it is requested after they have already sent the goods.

The important process introduced by the EUTR is the Due Diligence System (DDS). In this process, operators are required to submit documents related to product description, details of suppliers, compliance documents such as certification, assurance of compliance with legislation etc. The question submitted to the operators is if they have participated in the DDS. The majority answered affirmatively (76\%) while $24 \%$ stated they have no experience regarding the DDS. The documents requested to be delivered by the operators were various. The most frequent documentation required was the certification documents $(68 \%)$ (Figure 11).

Furthermore, in the second section, the respondents were asked if operators have recorded additional costs to implement and manage the EUTR requirements (e.g. administrative costs, adjustment costs, etc.). The percentage of respondents that have not recorded additional costs is $41.7 \%$ while $58.3 \%$ of all respondents have recorded additional costs. Those that answered affirmatively were asked to elaborate on their answer.

Most of the respondents expressed that the introduction of EUTR in the company has produced additional costs estimated, in percent term (such as $3 \%$, $10 \%, 20 \%$ ) or generically in "few thousand a year". Parts of these costs cover expenditures for translation, consultancy, or additional human resources with administrative education.

Section n. 3-Relationship between imported FLEGT licensed timber and timber of the EU origin

The third section of the questionnaire was created to present the stakeholder's opinions on the relationship of timber produced in Europe compared to those imported with FLEGT license. $80 \%$ of the respondents declared they don't have any knowledge of timber sales with FLEGT license. $20 \%$ of the respondents declared they know timber sales with FLEGT license. Those that answered affirmatively were asked the additional three questions. 


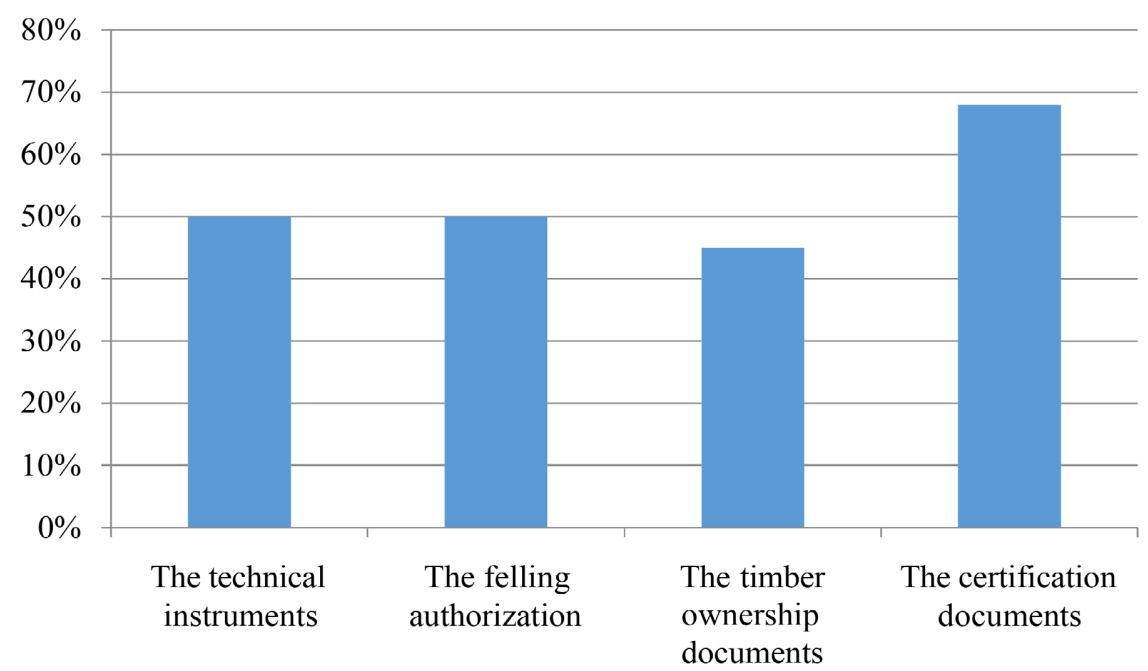

Figure 11. The documents the respondents were required to provide for the Due Diligence system.

The first additional question concerns if during their activities, operators have had the opportunity to see cases of harmonized administrative procedures between FLEGT and EUTR. The larger number of respondents (83.3\%) declared they didn't experience this type of harmonized administrative procedure between FLEGT and EUTR, while 26.7\% answered affirmatively.

The additional bureaucracy due to managing FLEGT timber importation compared to the EU timber production is the second additional question. No additional bureaucracy declares $66.7 \%$ of respondents while $33.3 \%$ of the respondents answered affirmatively.

The last additional question was if the marketing of timber licensed with the FLEGT license generated additional costs in addition to those produced by the management of DDS of the wood of EU origin. The percentage of respondents that answered affirmatively is $16.7 \%$, while $83.3 \%$ declared they didn't record additional costs.

\section{Section n. 4-Support for the implementation of EUTR}

The fourth section of the questionnaire was focused on the respondent's opinions about the support of legal authorities for the EUTR implementation. They were asked if they think that the operators in the forest sector need further support to fulfill their obligations under the EUTR. Respondents who think that operators need further support to fulfill the obligations under the EUTR are $62.5 \%$, while $37.5 \%$ of the respondents think further support is not needed. Those that answered affirmatively were asked to provide proposals on the measures that would be the most appropriate to ensure support. Respondents have provided many propositions. In the first place, they emphasize the importance of education. They pointed out that training should be ensured by the Competent $\mathrm{Au}$ thority, starting from small operators up to the supervisory authorities. However small operators have more difficulty obtaining a correct knowledge of the system and possess a lack of administrative skill to ensure a correct administration 
complying with EUTR rules. For them, simplification and support in management are needed.

Another important tool that needs to be provided is dedicated software for the global data exchange system. This should register the data of timber exported from countries with illegal logging problems with the timber imported data into the EU market and registered from customs agency. Most respondents suggest only making the EUTR mandatory to the operators who purchase timber from abroad.

\section{Section n. 5-Conformity checks}

The fifth section of the questionnaire was related to conformity checks. Firstly, the respondents were asked how many checks they have recorded by the Competent Authority (hereinafter CA) regarding compliance with EUTR requirements during the period from 3 March 2013 up to the date they have filled the questionnaire. Two different types of answers have been received: 1) they know that other companies are under checks thanks to "word of mouth"; 2) because of national and regional laws content norms and rules, they think that the conformity checks are not needed.

The other respondents produce the exact number of controls that were conducted in the related period (Figure 12).

Additionally, they were asked to elaborate on what types of controls were conducted. The respondents stated the controls were conducted by the Carabinieri Force of Forestry, Environmental and Agro-food units (CUFAA) and until 2016 by Forestry National Service. Controls included:

- checks on documentations and relative registers to imports from the previous year.

- control of custody for imported material with customs heading 4407.

- spot checks on timber imports (TARIC codes 44 control of the latest supplies).

- the documentation related to the EUTR.

- only checks performed by the audit are if the company has the PEFC certification and the checks that have been performed by the certification bodies.

After the elaboration, they were asked if they are aware of the situations when these offenses were followed by sanctions. $76.2 \%$ of the respondents were not aware of situations like these while $23.8 \%$ of the respondents answered affirmatively. Those that answered affirmatively were asked if they think that these sanctions are commensurate with the company's income capacity. $14.3 \%$ of the respondents answered that these sanctions commensurate with the company's income capacity while $85.7 \%$ think the sanctions don't commensurate. Those that answered negatively were asked to provide us with the elaborations. These operators said that sanctions are excessively expensive especially concerning the size of companies. The legislation tends to have a strong and negative impact on small and medium-sized companies. Some of them stated that sanctions in Italy are very high, while some of them think no sanction is commensurate with the free-standing companies. Another pointed out that penalties should be issued accordingly to the level of offense and that there is no such balance in current legislation. 


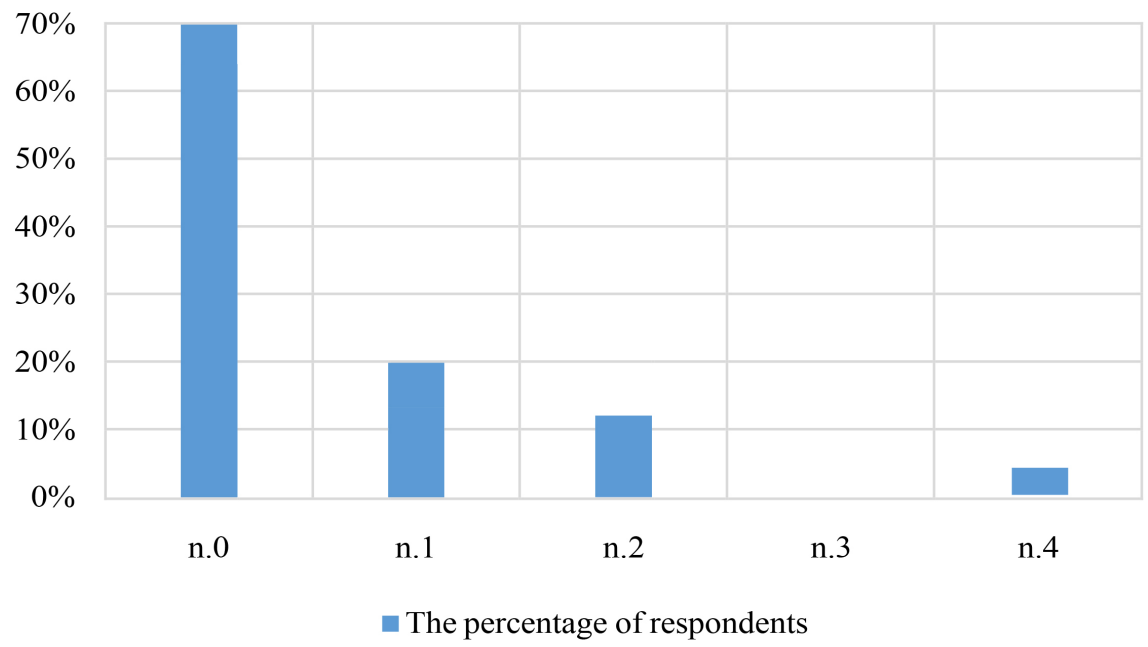

Figure 12. The percentage of the total respondents that reported the exact number of checks conducted by the competent authority.

The next point of interest of the questionnaire was if the respondents are aware of the information initiatives relating to the entry into force of the EUTR regulation. $56 \%$ of the respondents stated they are aware of such initiatives while $44 \%$ of the respondents were not aware of such initiatives. According to those that answered affirmatively, the responsible operators for these initiatives are:

- Trade associations,

- Consulting companies,

- AIEL-Associazione Artigani,

- FEDERLEGNO,

- Certification bodies,

- Monitoring organizations,

- LegnOK website and LegnOk 4.0 magazine,

- Local union of municipalities,

- Consortium such as CONLEGNO,

- In Lombardy the Association of Forestry Companies (ARIBL),

- Membership associations,

- Professional order and regions,

- Universities and courses organized by the ODAF in Torino.

Subsequently, we were interested if respondents, as a part of their business, did their best to disseminate EUTR information to other operators in the forest sector. $60 \%$ of the respondents disseminated the EUTR information to other operators while the other $40 \%$ of the respondents declared the opposite. Those that actively disseminated the information to other operators were asked about the methods they used. The most frequent method used by the respondents was "word-of-mouth" (53.4\%) while the others were less used (Figure 13).

\section{Section 6-EUTR as a marketing tool}

The sixth section investigated the EUTR from a marketing perspective. The respondents were asked if they think that the EUTR could be or become a useful 


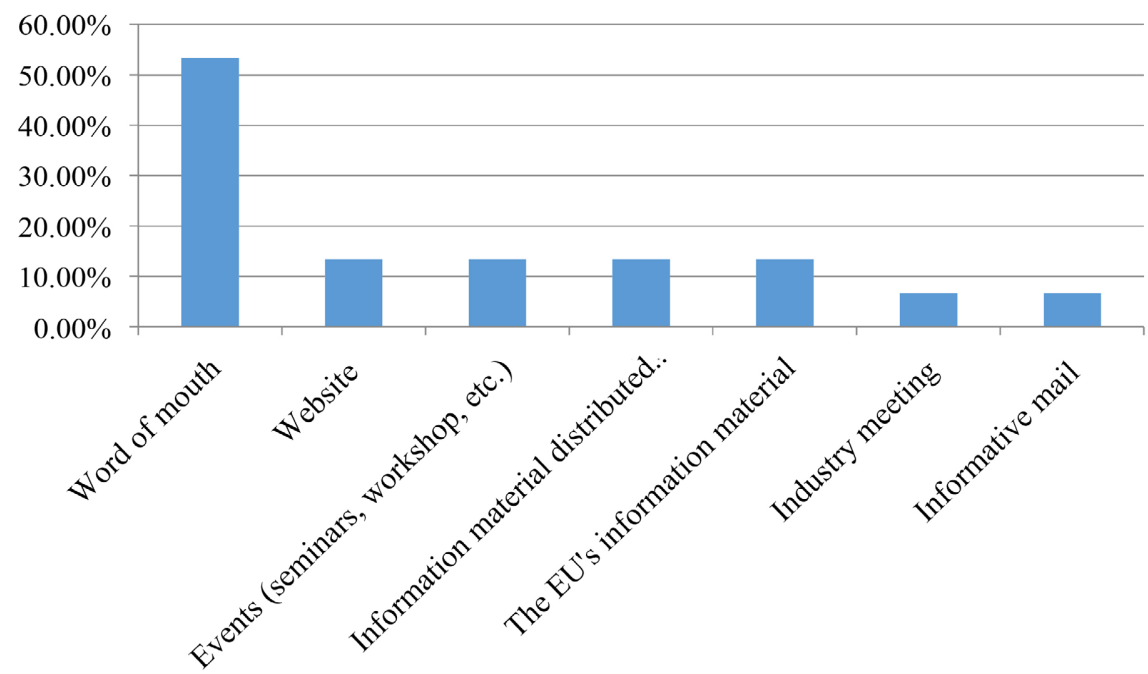

Figure 13. The methods of dissemination of EUTR information from respondents to the other operators.

marketing tool for companies they know or in the general sector. $72 \%$ of the respondents answered they don't see the EUTR as the marketing tool while 28\% of the respondents see it as an opportunity. Those that answered affirmatively were asked to elaborate us the way it could be seen as an efficient marketing tool.

Respondents have identified the importance of customer confidence. In their opinion, the EUTR increases customer's confidence and presents the company as a responsible choice. Others see an opportunity to increase the dissemination of information on a shared platform and to use it for a discourse on eco-sustainability. The majority of our respondents don't see the EUTR as a marketing tool because by them to do marketing it takes resources and therefore sufficiently large company sizes, which many forest companies don't have.

\section{Discussion}

This paper investigates the implementing process of EUTR in Italy and its effects on the foresters and timber operators in the national forest-timber system. To get this information, n. 106 questionnaires have been distributed to sensitive operators; unfortunately, the majority didn't take part in this study. However, the information collected is very relevant to understand the situation of EUTR in Italy and results are discussed in pair with results of other researches. In the following paragraphs, the key findings are presented.

\section{State of implementation on different levels of government}

According to biennial reports published by the European Commission (European Commission, 2018, 2020), continuous efforts are needed to ensure uniform and effective application of the EUTR. Our results support this statement. In Italy activities vary from region to region, however, the main activities at national scale that can be improved are:

- number of checks conducted by the Competent Authority;

- support by legal authorities for the EUTR implementation; 
- analyses of the difficulties that operators encountered to operate in compliance with the EUTR.

\section{Information availability about the EUTR among operators}

Köthke (2020) pointed out that operators in Germanys' timber-related sector were found to be unaware of the EUTR and less often compliant. Their low information status hints at uneven information availability. This was partially confirmed in our study because we had cases when operators inside the timber-related sector had been unaware of the EUTR. Although the operators in Italy showed a good basic knowledge about the EUTR implementation purpose, there are some cases when sawmills representatives stated that they have no knowledge about the EUTR and to proceed with the logging companies. This proves to us that there is still a gap in information flow to all related operators, even though some respondents declared that they receive EUTR news from many sources. Operators also pointed out this problem by their statements: "More information. The new producers are not informed enough".

\section{Bureaucracy and administration costs}

For private forest owners Pra (2015) found out that the EUTR implementation and efficiency are hindered by bureaucracy and transaction costs in contrast when their timber is sold on the domestic market, the timber prices on the domestic market don't change.

Results of this study have confirmed the Pra finding. Almost $60 \%$ of the respondents have recorded additional costs. They also pointed out additional bureaucracy has very high costs. The costs are evaluated in:

- "A few thousand euro a year"

- " $10 / 20 \%$-Costs for contract with the monitoring organization, costs for translation, costs for travel to suppliers, costs for consultancy/interpreter.

Pra (2015) also found out that the type and amount of information required for a Due Diligence varies significantly among respondent's countries. In our research, documents required by the CA for DDS purposes also vary from region to region.

\section{Cooperation with the Competent Authority}

Hein and Hoare (2014) surveyed EUTR Competent Authorities. According to them, availability of data regarding the number of operators has improved, facilitating the work of CAs in performing checks on companies.

According to our respondents, number of checks performed by CA varies among operators. CA hasn't carried out any checks to the major part of our respondents (64\%) while some of the respondents received n.4 checks. Some respondents even stated out that these types of controls are not needed emphasizing the role of the forest law: "We have the forest laws that control the legality of the cuts". This discrepancy between the numbers of checks carried out on different operators working in different regions suggests to us that more organization is needed to make the CA's conformity checks uniform throughout the whole Italy. Contrasting stakeholder's opinions about the size of penalties that have been issued by the CA, point out that penalties need to be adjusted accor- 
dingly to the company size in order to avoid negative impact on small and medium sized companies: "They are excessively expensive especially in relation to the size of the companies. The legislation tends to have a strong and negative impact on small and medium sized companies".

The second point according to our respondents is that penalties should be issued accordingly to the level of offense: "Because the claimed cases of illegal importation cannot be compared to the incorrect compilation of risk assessments".

\section{Concurrence with the FSC and PEFC}

There is contrast to Pra (2015) finding that third-party forest certification is not an asset when demonstrating compliance with the national legislation. Study results support Kistenkas (2013) finding that conventional command and control regulation, especially of the EU origin, can never be ruled out as a classic instrument on top of the instrumental pyramid of coerciveness, but private regulation is also needed as this transnational regulation might be even more successful as it takes place in the shadow of public law.

According to stakeholder's responses in Italy, third-party forest certification plays one of the most important roles to demonstrate compliance with the EUTR requirements, especially for the Due diligence System purposes. In our research, the respondent's percentage who labeled certification documents as obligatory documents for the DDS purposes is $68 \%$. They have emphasized the importance of third-party certification by their statements: "Suppliers that do not possess FSC or PEFC certification struggle to produce all the necessary documentation".

According to one of our respondents, representation of PEFC certification was sufficient to prove compliance with the EUTR requirements: "Only checks performed by the audit are if the company has the PEFC certification and the checks that have been performed by the certification bodies".

The third party certification should be used to access more information for risk mitigation as the final step of Due Diligence system. But, the third-party certification alone should never be a "green line" that proves compliance with the EUTR. It is not the primary purpose of certification and it has appeared way before the EUTR.

\section{EUTR as a marketing tool}

Even though the majority of our respondents don't see EUTR as a possible marketing tool there have been some suggestions on how this regulation could be used in this way. However, respondents say that only the larger companies might be using the EUTR as a marketing tool because they have the resources do to marketing strategy.

"To do marketing it takes resources and therefore sufficiently large company sizes, which many forest companies don't have".

The regulation itself increases confidence of customers:

- "A responsible company is always a better choice";

- "Greater customer's confidence".

Following these statements of the respondents, there may be a space for more 
research on how the EUTR could be used as a marketing tool.

\section{Conclusion}

FLEGT is a forest policy tool that aims to counter illegally felled timber to enter the world market. This timber is usually traded from the Asian and African regions. Complementary tool to FLEGT that aims to combat the trade of illegal timber inside the EU internal market is EUTR (Regulation 995/2010).

EUTR system involves all operators in the wood sector in the transformation and sale of wood products in the EU market. The initiative that has not yet reached 10 years from its adoption highlights numerous criticalities, both in the works already present in the scientific literature and this contribution dedicated to the Italian situation.

The survey conducted on a national scale through the dissemination of questionnaires recorded a low participation of operators, especially from the central-southern regions. This could be explained by still vague knowledge of the regulation given the timber trade on local markets; while for the Northern regions, from which the vast majority of completed questionnaires were received, this could be explained as a reaction to loss time for responding to investigations on the umpteenth administrative fulfillment that companies must take on daily by operating on international markets.

The picture that emerges from the results collected is that the EUTR, although proposed for morally and ethically valid purposes, doesn't have unanimous effectiveness. In particular, EUTR can generate a distortion of the market. Countries with a low risk of exporting illegal timber, once the agreed price has been acquired, have little interest in preparing useful documents for the customs requirements. Gaps in the documentation at this step become expenditures for importers. From this point of view, various operators applaud the role of certification schemes for sustainable forest management, which indirectly makes it possible to prevent the aforementioned problem.

Problem, however, does not exist with imports from countries at risk of exporting illegal timber, with which the EU has signed a voluntary agreement. In this case, there is a perfect alignment between FLEGT and EUTR bureaucracy and it doesn't generate additional costs, but only a more diligence in the store and archive documentations.

On the economic-financial level, however, the EUTR generates higher costs for companies and sometimes, in the larger companies, it has determined the conditions for hiring additional qualified units. For smaller companies, on the other hand, the initiative puts an already weak administrative structure in crisis, hence the need for support activities and staff qualification to allow the continuity of their activity.

The control of wood flows on the internal market, however, must not be based solely and exclusively on the control of the individual company or operator. It must also make use of computerized control systems, whose dataset must in- 
clude internal productions, as well as imports registered at customs and those received from the FLEGT process.

The control action monitored with the questionnaire proves to be somewhat irregular. There are some companies visited several times and others never. Obviously, the difficulties in implementing the EUTR put more burdens on smaller companies. With the same infringement with large companies, the penalties become heavier.

Although the traceability function of wood is recognized by this regulation, it is not valued in a marketing logic. This appears to be a contradiction. There are various regions that, having quality wood, aim at an enhancement of the productions through:

1) recognition marks also attributable to territorial qualities;

2) carbon surplus due to the use of local wood rather than imported wood.

These two tools, when combined, allow significant enhancement of the timber market. Still, these opportunities remain unexploited, either by a company, a group of companies, or territorial institutions.

One of the principles of the EUTR is multi-level governance. This approach is producing different implementations among the Italian regions. Ministry with competence in forest and forestry policies should act to ensure uniformity of norms and rules of this regulation throughout Italy.

The new law on forestry and forest supply chains that entered into force in 2018 aims at harmonizing various regional legislations and formulating national guidelines for the forestry sector. This may present an opportunity to harmonize the implementation of the EUTR as well. At this moment the hypothesis to use Italian EUTR implementation practices as a model for other Member states isn't verified, while it could be possible to use one of the efficient regions that have a relevant national and international timber trade.

The Italian EUTR system currently can be defined as a basic level. It is working only for satisfying the Regulation 995/2010 targets. This must be considered as the starting point; however three innovative topics could be developed in future: digitalization and computerization of EUTR certification, integration of EUTR certification with forest certifications schemes and other quality certifications, and use of EUTR in the marketing initiatives.

The current status of the EUTR Italian System in itself has no special characteristics that justify its replicate abroad. However, suggestions, to have a more efficient EUTR system, could be shared: adopting a national approach in EUTR systematization, and project " 2.0 version EUTR" where digitalization and computerization, integration and marketing are already included.

\section{Acknowledgements}

We are grateful to Italian stakeholders that took participation in this project by compiling questionnaires or sharing relevant information. This study did not obtain any external financial support. 


\section{Conflicts of Interest}

The authors declare no conflicts of interest regarding the publication of this paper.

\section{References}

Andrighetto, N., Pettenella, D., \& Masiero, M. (2015). Illegal Activities in the Italian Wood-Energy Sector and Potential Impacts on Regulation (Eu) 995/2010 (EU Timber Regulation). In IUFRO, 16th International Symposium (pp. 94-107). Transilvania University of Brașov.

Commission of the European Communities (2003). Forest Law Enforcement, Governance and Trade (FLEGT) Proposal for an EU Action Plan. 251 Final, Brussels, 21.5.2003.

Economic and Social Council (1997). Report of the Ad Hoc Intergovernmental Panel on Forests. Commission on Sustainable Development, Fifth Session, 7-25 April 1997, E/CN.17/1997/12.

European Commission (2013). Environment: New Timber Regulation Comes into Force. https://ec.europa.eu/commission/presscorner/detail/en/IP_13_175

European Commission (2018). Regulation (EU) No 995/2010 of the European Parliament and of the Council of 20 October 2010 Laying down the Obligations of Operators Who Place Timber and Timber Products on the Market (the EU Timber Regulation). Report from the Commission to the European Parliament and the Council, Biennial Report for the Period March 2015-February 2017, COM/2018/668 Final.

European Commission (2020). Regulation (EU) No 995/2010 of the European Parliament and of the Council of 20 October 2010 Laying down the Obligations of Operators Who Place Timber and Timber Products on the Market (the EU Timber Regulation). Report from the Commission to the European Parliament and the Council, Biennial Report for the Period March 2017-February 2019, COM (2020) 629 Final.

Glen, S. (2014). Snowball Sampling: Definition, Advantages and Disadvantages. https://www.statisticshowto.com/probability-and-statistics/statistics-definitions/snowb all-sampling

Hein, J., \& Hoare, A. (2014). EUTR Competent Authority Survey. Energy, Environment and Resource Governance. Chatham House.

Kistenkas, F. (2013). Concurring Regulation in European Forest Law. Forest Certification and the New EU Timber Regulation. GAIA-Ecological Perspectives for Science and Society, 22, 166-168. https://doi.org/10.14512/gaia.22.3.7

Köthke, M. (2020). Implementation of the European Timber Regulation by German Importing Operators: An Empirical Investigation. Forest Policy and Economics, 111, Article ID: 102028. https://doi.org/10.1016/j.forpol.2019.102028

Krott, M. (2005). Forest Policy Analysis. Springer.

Matsson, K. (2015). The Impact of the EU Timber Regulation on the Bosnia and Herzegovinian Export of Processed Wood. Master Thesis, Swedish University of Agricultural Sciences Faculty of Forest Sciences.

Oliver, R. (2011). Statistics-Italy 2011 Timber Trade Monitoring in Support of Effective, Efficient and Equitable Operation of the EU Timber Regulation (EUTR). European Timber Trade Federation, Department for International Development.

Pra, A. (2015). Survey among Private Forest Owners on the European Union Timber Regulation (EUTR) Implementation.

Yanow, D. (2007). Interpretation in Policy Analysis: On Methods and Practice. Critical Policy Studies, 1, 110-122. https://doi.org/10.1080/19460171.2007.9518511 